\title{
PRÁTICAS COLABORATIVAS IDENTIFICADAS NO ENSINO BÁSICO: UM ESTUDO DE CASO EM MINAS GERAIS
}

\author{
COLLABORATIVE PRACTICES IDENTIFIED AT THE JUNIOR AND THE HIGH \\ SCHOOL: A CASE STUDY IN MINAS GERAIS
}

PRÁCTICAS COLABORATIVAS IDENTIFICADAS EN LA ENSEÑANZA BÁSICA: UN ESTUDIO DE CASO EM MINAS GERAIS

\author{
Ana Paula Bossler \\ E-mail: paula.bossler@gmail.com
}

\author{
Pedro Zany Caldeira \\ E-mail: pedro.caldeira@uftm.edu.br \\ Universidade Federal do Triângulo Mineiro - UFTM \\ Agência de fomento: FAPEMIG - Processo APQ-03356-12
}

\begin{abstract}
RESUMO
Este estudo teve como objetivo conhecer as práticas colaborativas desenvolvidas entre professores brasileiros do ensino básico. Uma pesquisa on-line buscou conhecer as práticas de ensino dos professores e o respectivo grau de colaboração. A pesquisa foi respondida por 79 professores do ensino básico, principalmente do Estado de Minas Gerais. Os resultados apontam para que, muito embora os participantes conheçam as vantagens das práticas de instrução colaborativa, eles não cooperam entre si. $\mathrm{Na}$ verdade, eles nem compartilham planejamentos de aulas e muito menos materiais educacionais. As poucas práticas colaborativas observadas incluíram uma Feira de Cultura escolar e uma Feira de Conhecimento. No entanto, nas observações realizadas a esses eventos, as práticas observadas não podiam ser classificadas como colaborativas porque: as equipes de alunos competiam entre si, os alunos não eram encorajados pelos professores a olhar o trabalho dos seus colegas e as feiras resultaram somente em coleções não relacionadas de tarefas e em um grande amontoar de pessoas. Em um terceiro momento, foram realizadas entrevistas a quatro professores, que possibilitaram entender por que os professores geralmente não estão envolvidos em trabalhos e tarefas colaborativas: por medo de críticas (eles temem que seus colegas critiquem seus planos de aula ou seus materiais educacionais) e por medo da concorrência (eles temem que seus colegas possam assumir o seu cargo no futuro).
\end{abstract}

PALAVRAS-CHAVE: Instrução colaborativa. Medo da crítica. Medo da concorrência.

\section{ABSTRACT}

This study aimed to know the collaborative practices developed among K12 Brazilian teachers. An online survey on teaching practices asked for the teachers' practices regarding collaboration, as sharing of lesson plans and educational materials. The survey was completed by $79 \mathrm{k12}$ teachers, mainly from the state of Minas Gerais. Although the participants know the advantages of collaborative teaching practices, they do not cooperate with each other. In fact, they even do not share instruction plans and much less educational materials. The few collaborative practices reported included a school Fair of Culture and a Fair of Science/Knowledge. However, in site observations showed that those practices could not be classified as collaborative because: 1. the student's teams compete among themselves, 2. students are not encouraged to look at their classmate's work, 3. the Fairs result only in a collection of tasks and a big gathering of people. Deep interviews with four teachers have made it possible to understand why teachers are not usually involved in collaborative work and tasks: fear of critics (they fear their colleagues criticize their lesson plans or their educational materials) and fear of competition (they fear their colleagues will take up their jobs in the future).

KEYWORDS: Collaborative instrction. Fear of criticism. Fear of competicion.

\begin{tabular}{|l|l|l|l}
\hline v.11 & n.3
\end{tabular}



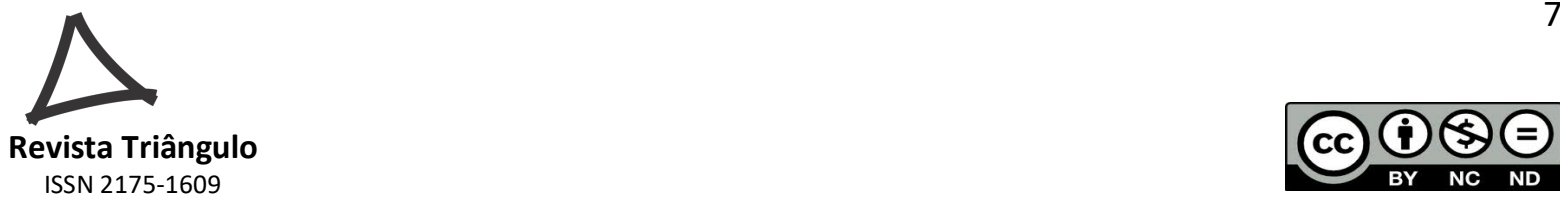

\section{RESUMEN}

Este estudio tuvo como objetivo conocer las prácticas colaborativas desarrolladas entre profesores brasileños de la enseñanza básica. Una encuesta en línea buscó conocer las prácticas colaborativas de enseñanza de los maestros. La encuesta fue respondida por 79 maestros de enseñanza básica, principalmente del estado de Minas Gerais. Los resultados apuntan a que, aunque los participantes conocen las ventajas de las prácticas de enseñanza colaborativa, no cooperan entre sí. En realidad, no comparten planes de clases y mucho menos materiales educativos. Las pocas prácticas colaborativas observadas incluyeron una Feria de Cultura escolar y una Feria de Conocimiento. Sin embargo, en las observaciones realizadas a estos eventos, las prácticas observadas no podían ser clasificadas como colaborativas porque: los equipos de alumnos competían entre sí, los alumnos no eran alentados por los maestros a mirar el trabajo de sus colegas y la feria resultou sólo en una grande coleccione de tareas no relacionadas y un gran montón de personas. En un tercer momento, se realizaron entrevistas a cuatro profesores, que posibilitaron entender por qué los profesores generalmente no están involucrados en trabajos y tareas colaborativas: por miedo a críticas (ellos temen que sus colegas critiquen sus planes de aula o sus materiales educativos) y por miedo a la competencia (ellos temen que sus colegas puedan asumir su cargo en el futuro).

PALABRAS-CLAVE: Enseñanza colaborativa. Miedo a la crítica. Miedo a la competición.

\section{INTRODUÇÃO}

A pesquisa tem demonstrado que a prática cotidiana do professor pode ser bastante solitária. Entretanto, há evidências empíricas que, quando os professores trabalham em cooperação com seus pares, seus alunos têm resultados acadêmicos mais altos (KUH, 2016). Neste artigo pretende-se identificar e analisar as práticas de colaboração desenvolvidos por docentes brasileiros do ensino básico, buscando verificar se os professores desenvolvem práticas e processos colaborativos entre eles, tanto no nível do ensino quanto no nível de aprendizagem. As questões desenvolvidas incluíram temáticas como, por exemplo, a predisposição dos docentes do ensino básico para desenvolverem práticas pedagógicas colaborativas com outros colegas ou o engajamento de professores e alunos na concepção e desenvolvimentos de tarefas colaborativas no ensino básico.

\section{REFERENCIAL TEÓRICO}

Os professores como profissionais têm um forte sentimento de solidão, já que seu trabalho exige longos ciclos de isolamento, como por exemplo, nas fases de planejamento ou de avaliação e na execução da aula a portas fechadas (GROSSMAN, WINEBURG, WOOLWORTH, 2001; KUH, 2016). Nas escolas, os professores interagem principalmente com os alunos, limitando a interação com colegas ao breve tempo passado na sala dos professores ou cumprimentos ocasionais nos corredores (MCINERNY, 2016). 
No entanto, nas últimas três décadas, os professores são crescentemente encorajados a colaborar entre si, tanto em relação à aprendizagem dos alunos (LASSONDE, ISRAEL, 2010) quanto aos objetivos de instrução dos professores (PONTE, SEGURADO, OLIVEIRA, 2003).

No início, a pesquisa educacional centrou-se na aprendizagem colaborativa, incluindo a aquisição de conhecimento e desenvolvimento de habilidades e atitudes próprias de quando os alunos exploram juntos um tópico (GRAHAM, SCARBOROUGH, 1999). A colaboração está em andamento quando dois ou mais indivíduos com habilidades complementares interagem para criar uma compreensão compartilhada de informações que nenhum deles possuía anteriormente ou seria alcançado sozinho (SCHRAGE, 1992), pois o conhecimento é construído socialmente, facilitado pela interação, avaliação e cooperação de pares (HILTZ, BENBUNAN-FICH, COPPOLA et al., 2000).

O aprendizado colaborativo permite que os alunos desenvolvam (HUGHES, WICKERSHAM, RYAN-JONES, SMITH, 2002):

1. habilidades de raciocínio;

2. uma compreensão profunda do conteúdo aprendido;

3. a capacidade de compreender situações e eventos na perspectiva dos outros e;

4. relacionamentos positivos e ajuda mútua entre eles.

A pesquisa educacional também se concentra no desenvolvimento de trabalho colaborativo entre professores, entre professores e pesquisadores, entre professores e alunos ou entre professores e pais (PONTE et al., 2003).

As pesquisas desenvolvidas por Lave e Wenger (Aprendizagem Situada - LAVE, WENGER, 1991 - e Comunidade de Prática - WENGER, 1998, 2010, WENGER, MCDERMOTT, SNYDER, 2002) e Donald Schön (Prática Reflexiva - SCHÖN, 1987) influenciaram os estudos sobre o desenvolvimento de práticas pedagógicas colaborativas entre professores.

Uma comunidade de prática é um grupo de pessoas que compartilham uma preocupação, um conjunto de problemas ou uma paixão por um tema e que aprofundam seus conhecimentos e habilidades interagindo uns com os outros de forma contínua (WENGER, MCDERMOTT, SNYDER, 2002). Aprender in locu e aprender fazendo são a base das comunidades de prática, 
porque aprender uma profissão é um processo inerentemente social (LAVE, WENGER, 1991).

A aprendizagem situada ocorre nos contextos sociais da vida do professor, focalizando a relação inextricável entre conhecimento e prática, a saber, a prática social. Assim, a aprendizagem situada considera que aprender a ser professor envolve (LAVE, WENGER, 1991):

1. ter uma compreensão abrangente do professor como uma pessoa completa e total, e não apenas de 'entregar' um conjunto de conhecimentos factuais do mundo a seus alunos;

2. desenvolver uma atividade no e com o mundo, e;

3. tendo em atenção uma perspectiva em que o agente, a atividade e o mundo se formam mutuamente.

Aprender, de acordo com essa abordagem, não é apenas uma prática situada (como um processo que ocorre por acaso em um determinado lugar), mas é parte integrante de uma prática social no mundo, como é experimentada pelo professor enquanto está a aprender a ser professor (LAVE, WENGER, 1991).

Embora esta abordagem não pretenda fazer uma análise dos tipos de aprendizagem que ocorrem nas escolas (e muito menos ser um método pedagógico ou uma técnica de ensino LAVE, WENGER, 1991), aplica-se à formação de professores, particularmente aos professores iniciantes.

Assim, ensinar a ser professor pode ser analisado de acordo com as comunidades de prática e a abordagem de aprendizagem situada, uma vez que ambas são práticas sociais inseridas em uma comunidade específica de prática.

Desde o início da década de 1980, Schön (1987) mostrou que a formação de professores deve ter uma forte parte reflexiva, muito além do que é tradicional implicando geralmente apenas o conhecimento disciplinar centrado (ZEICHNER, LISTON, 1996).

A formação reflexiva dos professores parte de alguns princípios básicos muito simples, separando o que é conhecimento-por-ação (conhecimento mobilizado para ação e que é o foco da formação tradicional de professores) de reflexão-em-ação (em que os professores pensam

\begin{tabular}{|l|l|l}
\hline v.11 & n.3
\end{tabular}


sobre o que eles estão fazendo ao fazê-lo). Mais, a formação reflexiva dos professores deve ser feita não só através da reflexão-em-ação, mas também através da reflexão-sobre-a-ação e reflexão-sobre-a-reflexão-em-ação (SCHÖN, 1987).

Mas, quando é analisada a possibilidade de aplicar este modelo à formação de professores, diversas barreiras surgem: a falta de compreensão dos formuladores de políticas sobre a importância da formação de professores reflexivos, a incapacidade das universidades de oferecerem formação reflexiva para seus licenciandos, preferência pela formação disciplinar específica em detrimento da formação para a prática da profissão, grande número de estagiários por supervisor, formação inadequada ou desajustada dos supervisores, carga de trabalho excessiva dos supervisores e estagiários ou, inclusivamente, o desinteresse dos professores em formação para o ensino e para a prática futura da profisssão.

\section{MATERIAIS E MÉTODOS}

Em um primeiro momento, foi desenvolvida uma pesquisa on-line (julho-novembro de 2016) sobre práticas colaborativas e o uso de tecnologia para desenvolver práticas colaborativas entre professores do ensino básico. A pesquisa teve duas perguntas pessoais (idade e gênero), três questões profissionais (anos como professores e formação) três sobre práticas colaborativas (produção de conteúdo / materiais relacionados à escola, disposição para compartilhar conteúdos / materiais relacionados à escola produzidos, participação em rede social em Educação em Ciência) e dois sobre usos da tecnologia (o que usam na sala de aula e em que tarefas usam a tecnologia).

Em um segundo momento, os autores observaram as práticas colaborativas entre professores e alunos em uma escola de ensino básico (anos finais do Ensino Fundamental e Ensino Médio). A observação foi feita no segundo semestre de 2016 e focada nos processos colaborativos que os alunos realizam durante uma Feira de Cultura (apresentações pelos alunos do $6^{\mathrm{a}}$ ano sobre a cultura da antiga China ou da antiga Índia) e uma Feira de Conhecimento (por alunos do $6^{\circ}$ ao $9^{\circ}$ ano, consistindo em projetos de Ciência relacionados a Água e Sustentabilidade).

A observação teve como objetivo identificar e analisar as práticas colaborativas realizadas pelos professores na definição, design e desenvolvimento das Feiras e identificar e analisar práticas colaborativas realizadas tanto por professores quanto por estudantes para a concepção e desenvolvimento das feiras. 
Em um terceiro momento, os pesquisadores realizaram entrevistas em profundidade com quatro professores, tentando entender por que os professores brasileiros geralmente têm uma baixa adesão ao desenvolvimento de tarefas pedagógicas colaborativas.

\section{ANÁLISE DOS DADOS E RESULTADOS}

\subsection{A Pesquisa}

As respostas dos participantes foram coletadas através de Monkey Surveys e um total de 79 professores de Ciências participaram, dos quais 78,6\% eram do sexo feminino e 21,4\% eram do sexo masculino, 21,4\% tinham menos de 25 anos, 64,3\% tinham entre 25 e 45 anos e $14,3 \%$ tinham mais de 55 anos.

Profissionalmente, a amostra tinha 46,9\% de professores com menos de um ano de prática ou entre 1-3 anos como professores, 14,3\% entre 3-5 ou 5-10 anos de prática profissional e $35,7 \%$ com mais de 10 anos como professores.

Mais de um terço dos professores (42,9\%) desenvolveram, em algumas ocasiões, conteúdo / material relacionado à escola e usaram-no na sala de aula, e mais da metade $(57,1 \%)$ querem no futuro produzir conteúdo / material relacionado ao ensino.

$\mathrm{Na}$ Tabela 1 podemos observar a vontade dos professores de compartilhar materiais que produzem (no presente e no futuro).

\begin{tabular}{|l|c|}
\hline \multicolumn{1}{|c|}{ Disposição para compartilhar conteúdo / material } & $\%$ \\
\hline Sim, eu já compartilho as minhas produções & 21,4 \\
\hline $\begin{array}{l}\text { Sim, estou disponível para compartilhar as minhas } \\
\text { produções }\end{array}$ & 64,3 \\
\hline $\begin{array}{l}\text { Não, apenas se outros professores compartilharem comigo } \\
\text { as suas produções }\end{array}$ & 14,3 \\
\hline
\end{tabular}

Tabela 1. Disposição dos professores para compartilharem as suas produções

Pode-se observar que a maioria dos professores $(85,7 \%)$ afirma já compartilhar ou estar disposto a compartilhar as suas produções no futuro.

No entanto, apenas cerca de um terço dos professores $(37,4 \%)$ se consideram usuários ativos das redes sociais profissionais (ver Tabela 2). 


\begin{tabular}{|l|c|}
\hline Conhece e faz parte de alguma rede social profissional? & $\mathbf{\%}$ \\
\hline Não conheço e não faço parte & 45,9 \\
\hline Não, conheço mas não quero fazer parte & 18,4 \\
\hline Sim, conheço e participo & 35,7 \\
\hline
\end{tabular}

Tabela 2. Conhecimento e uso dos professores de redes sociais profissionais

Assim, 85,7\% dos professores participantes neste primeiro momento dizem já compartilhar ou estar disponíveis para compartilhar conteúdos / materiais, mas apenas 35,7\% participam em redes sociais profissionais. Metade dos professores demonstram vontade de compartilhar mas apenas localmente (com colegas da sua escola ou região), pois desconhecem o potencial das redes sociais profissionais para o desenvolvimento de parcerias e de trabalho colaborativo.

\subsection{As Observações}

Os autores observaram as práticas colaborativas em duas ocasiões diferentes: em uma Feira de Cultura (envolvendo um professor e 42 alunos do $6^{\mathrm{a}}$ ano) e em uma Feira de Conhecimento (envolvendo 32 professores e 882 alunos dos $6^{\text {a }}$ ao $9^{\mathrm{a}}$ ano).

Ambas as observações se centraram nas práticas colaborativas dos alunos, tendo a última observação também se concentrado nas práticas colaborativas dos professores.

Feira de Cultura - os alunos de uma turma do $6^{\circ}$ ano tiveram que preparar e apresentar um trabalho (6 elementos em cada grupo) sobre características culturais (por exemplo, arquitetura, trajes típicos, gastronomia, mitos ou música), de duas diferentes culturas: antiga China e antiga Índia. Seis grupos de estudantes optaram por apresentar a cultura da China antiga (uma das características acima listadas por grupo) e um sétimo grupo optou por apresentar a cultura da antiga Índia.

Os alunos de todos os grupos (Grupos I a VII) fizeram um primeiro encontro em uma das aulas, distribuindo diferentes temas ou subtemas entre eles (um tema / característica por aluno), os alunos prepararam os temas individualmente em casa e se encontraram uma 
segunda vez em outra aula antes da apresentação do trabalho, para compartilharem os materiais finais que prepararam.

Em dois grupos, os alunos (Grupos III e V) fizeram um primeiro encontro em uma das aulas, definiram o que eles iriam apresentar, discutiram suas idéias com o professor, se encontraram várias vezes dentro e fora da escola para pesquisar e selecionar a informação que iriam apresentar, discutiram suas idéias mais uma vez com o professor e voltaram novamente para pesquisar e selecionar informações.

Em outros dois grupos de alunos (Grupos I e VI), observou-se que metade dos alunos participou da fase de preparação e a outra metade não se envolveu com o trabalho.

O professor, na fase de preparação durante as aulas, circulou entre os diferentes grupos de alunos, coletando idéias e dando sugestões. Todos os grupos fizeram as suas apresentações na mesma aula.

Feira de Conhecimento - os alunos do $6^{\circ}$ ao $9^{\circ}$ ano e do $1^{\circ}$ ao $3^{\circ}$ ano do Ensino Médio, tiveram que preparar e entregar um projeto de Ciências (6 alunos por grupo) sobre Água e Sustentabilidade, onde deveriam incluir um artefato funcional relacionado ao tema. O projeto de Ciências foi o momento de avaliação final do ano letivo para todos os alunos da escola.

Participaram na Feira 15 turmas do Ensino Fundamental (do $6^{\circ}$ ao $9^{\circ}$ ano - no total de 105 grupos) e nove turmas do Ensino Médio (no total de 63 grupos)

Os alunos desenvolveram os seus projetos em tempos letivos especificamente atribuídos a essa tarefa, mas também alguns deles precisaram se encontrar fora da escola para preparar suas apresentações. As observações das interações em sala de aula permitiram identificar quatro níveis de colaboração entre os alunos, sem que fosse identificada uma diferença entre os grupos de alunos do Ensino Fundamental e os grupos de alunos do Ensino Médio (ver tabela 3).

\begin{tabular}{|c|c|}
\hline Níveis de colaboração entre os alunos & $\begin{array}{c}\text { \% de grupos } \\
\text { (Total - 168) }\end{array}$ \\
\hline Colaboração elevada (pesquisa e seleção colaborativa de & $25 \%$ \\
\hline
\end{tabular}

\begin{tabular}{|l|l|}
\hline v.11 & n.3
\end{tabular}




\begin{tabular}{|l|c|}
\hline informação e design e construção coletiva do artefato) & \\
\hline $\begin{array}{l}\text { Colaboração média (pesquisa e seleção colaborativa de } \\
\text { informação ou design e construção coletiva do artefato), } \\
\text { com pelo menos um teste do artefato antes da sua } \\
\text { apresentação à comunidade escolar. }\end{array}$ & $14,9 \%$ \\
\hline $\begin{array}{l}\text { Colaboração baixa (design coletivo do artefato), sem um } \\
\text { teste do artefato previamente à sua apresentação à }\end{array}$ & $21,4 \%$ \\
comunidade escolar. & \\
\hline $\begin{array}{l}\text { Sem colaboração, nem em relação à pesquisa e seleção } \\
\text { colaborativa de informação nem em relação ao design e } \\
\text { construção coletiva do artefato. }\end{array}$ & $38,7 \%$ \\
\hline
\end{tabular}

Tabela 3. Descrição dos níveis da colaboração entre os alunos

Assim, um pouco menos de 40\% de todos os grupos de estudantes desenvolveram níveis de colaboração altos / médios, e a maioria dos grupos de alunos (mais de 60\%) apresentou pouca ou nenhuma colaboração na preparação dos projetos de Ciências.

As observações no local em que decorreram as apresentações mostraram que o nível de colaboração entre os diferentes grupos de alunos foi muito baixo, especialmente porque as equipes de alunos competiam entre si. No dia da Feira, os alunos não foram encorajados a olhar para os trabalhos desenvolvidos pelos seus colegas e, por último, mas não menos importante, as Feiras resultaram apenas em uma coleção de tarefas desenvolvidas competitivamente em pequenos grupos e em uma grande aglomeração de pessoas.

Foram identificadas duas tarefas colaborativas que os professores desenvolveram entre si: 1 . definição do tema da Feira de Conhecimento e 2. Marcação do dia em que a Feira iria decorrer. Os professores demonstraram disponibilidade para auxiliarem os seus alunos no desenvolvimento dos seus projetos, mas de forma totalmente isolada: cada professor apenas auxiliou os seus grupos de alunos.

\subsection{As Entrevistas}

De modo a perceber-se os baixos níveis de colaboração detectados nos dois momentos anteriores, foram feitas duas perguntas a quatro professores que aceitaram ser entrevistados: 
1. Por que você acha que os professores não colaboram ou colaboram muito pouco entre si?

2. Por que você não compartilha seus planos de aulas ou suas produções de conteúdos / materiais relacionados ao ensino?

Os principais motivos que os entrevistados invocaram para explicar o baixo nível de colaboração entre professores são o individualismo extremo do povo brasileiro ("O povo brasileiro é muito individualista, as pessoas pensam apenas em termos de si mesmos, suas famílias e, finalmente, seus amigos - ninguém mais importa!").

Mas quando os professores foram perguntados por que eles não compartilham seus planos de aula ou produções, eles afirmam ter medo de críticas ("Outros podem julgar negativamente o meu trabalho") ou medo da concorrência ("Se eu der tudo o que tenho deixo de ter vantagem sobre os outros professores" - com potenciais impactos negativos sobre a sua carreira profissional - "Outros professores podem assumir meu cargo no futuro").

Dois dos professores também disseram que, como professores iniciantes, eles começaram a compartilhar planos de aula e seus conteúdos / materiais relacionados ao ensino, mas eles rapidamente deixaram de o fazer, pois seus colegas não compartilhavam com eles o seu trabalho ("O compartilhamento deve ser um caminho de dois sentidos!").

\section{CONSIDERAÇÕES FINAIS}

O principal resultado aqui detectado é o reduzida nível de colaboração entre professores. No entanto, parece que os professores que já conhecem e usam redes sociais profissionais (principalmente centradas em áreas disciplinares específicas) e desenvolvem seus próprios conteúdos / materiais relacionados ao ensino estão mais dispostos a compartilhar suas produções. Assim, os professores participantes na pesquisa têm uma noção muito ténue da Comunidade de Prática a que pertencem (LAVE, WENGER, 1991; WENGER et al., 2002), pois apenas uma minoria pertence a redes sociais profissionais $(35,7 \%)$ ou entende a importância de compartilhar as suas produções profissionais (21,4\%). Estes indicadores mostram também claramente, em primeiro lugar, a reduzida predisposição para considerar os contextos escolares como locais de aprendizagem situada (LAVE, WENGER, 1991), aprendizagem nas situações práticas do exercício da profissão e, em segundo lugar, a ausência de momentos estruturados para a reflexão-em-ação ou reflexão-sobre-a-ação (SCHON, 1987). 
A ausência de indicadores de existência de Comunidades de Prática nas escolas (WENGER et al., 2002), de aprendizagem pelos professores em situações práticas do exercício da profissão (LAVE, WENGER, 1991) e de momentos estruturados de reflexão-em-ação e de reflexãosobre-a-ação (SCHON, 1987) são, também, demonstrativos do isolamento vivido pelos professores nas escolas (GROSSMAN et al., 2001, KUH, 2016) e da necessidade de efetuar incluir essas temáticas na formação continuada dos professores.

Para além disso, os resultados mostram a necessidade de demonstrar, tanto aos professores quanto aos alunos, os benefícios do trabalho colaborativo, especialmente quando se visa o melhor desempenho educacional dos alunos (KUH, 2016; LASSONDE, ISRAEL, 2010). A colaboração dos professores deve ser abordada não só no nível disciplinar, mas também no nível da escola, já que algumas pesquisas mostraram que a realização educacional dos alunos é "maior nas escolas onde os professores relatam altos níveis de responsabilidade coletiva para o aprendizado dos alunos" (KUH, 2016, p. 293; ver também LEE, SMITH, 1996).

No sistema educacional de ensino básico brasileiro, os professores, além de suas tarefas em sala de aula / escola (reuniões), são chamados a participar de sessões semanais de formação continuada em módulos. Em cada uma dessas sessões, a direção / supervisão define o tópico a ser trabalhado. De entre a multiplicidade de tópicos a abordar, poderiam ser incluídas as seguintes questões: "Como implementar processos de colaboração efetivos entre professores", "Como usar a tecnologia para aumentar os níveis de colaboração entre professores" ou "Como projetar cenários de ensino para garantir que os alunos desenvolvam autênticos processos de aprendizagem e de trabalho colaborativos". Em geral, estes são espaços para manter os professores atualizados sobre legislação educacional e regras da escola.

Assim, espaços e tempos privilegiados de formação continuada dos professores do ensino básico são muitas das vezes dedicados a atualizar informação e, eventualmente, esclarecer as relações de poder dentro da escola, no lugar do aprofundamento de temáticas que podem ter impactos positivos quer nos processos de ensino, quer nos processos de aprendizagem. Deste modo, as escolas dificilmente se tornarão locais de partilhe de saberes e materiais, emergindo Comunidades de Prática (WENGER et al., 2002), apesar de estarem criadas as condições (nos módulos) para o desenvolvimento de processos de aprendizagem situada (LAVE, WENGER, 1991) onde se poderia privilegiar momentos de reflexão-em-ação ou de reflexão-sobre-a-ação (SCHON, 1987). 
Embora os resultados mostrem claramente que um pouco mais de um quinto dos participantes dos professores neste estudo já compartilhou suas produções relacionadas ao ensino, e quase dois terços estão dispostos a compartilhar futuras produções relacionadas à instrução, o nível real de colaboração entre professores é muito baixo. As observações também confirmaram que os professores não desenvolvem processos de trabalho colaborativo ou têm poucos processos colaborativos entre si, o que se parece refletir na estruturação tendencialmente individualizada dos processos de aprendizagem e de trabalho dos alunos, conforme observado nas fases de preparação das Feiras de Cultura e de Conhecimento, nomeadamente na concepção e construção dos projetos científicos, e nos próprios dias das Feiras.

As sessões de formação continuada por módulos semanal dos professores poderiam e deveriam abordar questões de colaboração, tanto entre professores quanto entre estudantes, uma vez que comprovadamente o desenvolvimento de ambientes colaborativos em contextos educacionais exercem impactos muito positivos nos processos de ensino dos professores e nas aprendizagens dos alunos.

\section{REFERÊNCIAS}

GRAHAM, M., SCARBOROUGH, H. Computer mediated communication and collaborative learning in an undergraduate distance education environment. Australian Journal of Educational Technology, v. 15, n. 1, p. 20-46, 1999. Disponível em http://www.ascilite.org.au/ajet/ajet15/graham.html. Acesso em 22 jan. 2004. doi: https://doi.org/10.14742/ajet.1845

GROSSMAN, P., WINEBURG, S., WOOLWORTH, S. (2001). Toward a Theory of Teacher Community. The Teachers College Record, v. 103, p. 942-1012, 2001. doi:10.1111/0161$\underline{4681.00140}$

HILTZ, S. R., BENBUNAN-FICH, R., COPPOLA, N., ROTTER, N., \& TUROFF, M. Measuring the importance of collaborative learning for the effectiveness of ALN: a multimeasure, multi-method approach. Journal of Asynchronous Learning Networks, 4 (2-3), 2000. Disponível em $<$ http://www.aln.org/alnweb/journal/jaln-vol4issue2-3.htm>. Acesso em: 27 mai. 2015.

HUGHES, S.E., WICKERSHAM, L.E., RYAN-JONES, D.L., SMITH, S.A. Overcoming social and psychological barriers to effective online collaboration. Educational Technology and Society, v. 5, n. 1, p. 86-92, 2002.

KUH, L. P. Teachers talking about teaching and school: collaboration and reflective practice via Critical Friends Groups. Teachers and Teaching: theory and practice, v. 22, n. 3, p. 293-314, 2016. doi:https://doi.org/10.1080/13540602.2015.1058589 
LASSONDE, C. A., ISRAEL, S. E. Teacher Collaboration for Professional Learning: Facilitating Research, Study and Inquiry Communities. São Francisco, CA: Jossey-Bass, 2010 .

LAVE, J., WENGER, E. Situated Learning: Legitimate Peripheral Participation. Cambridge, MA: Cambridge University Press, 1991.

LEE, V.E., \& SMITH, J. Collective responsibility for learning and its effects on gains in achievement and engagement for early secondary students. American Journal of Education, v. 104, p. 103-147, 1996.

MCINERNY, C. The Surprising Loneliness of Teaching. StateImpact Indiana, Guest Blogm 2016. Disponível em <http://indianapublicmedia.org/news/guest-blog-surprising-lonelinessteaching-96902/ . Acesso em 12 jun. 2017.

PONTE, J. P., SEGURADO, I., \& OLIVEIRA, H. What happens when pupils work on mathematical investigations? In A. Peter-Koop, V. Santos-Wagner, C. Breen, \& A. Begg (Eds.), Working towards a common goal: Collaborative paths in mathematics teacher education (pp. 85-97). Dordrecht: Kluwer, 2003.

SCHÖN, D. A. Educating the reflective practitioner. São Francisco, CA: Jossey-Bass, 1987.

SCHRAGE, M. Shared Minds: The New Technologies of Collaboration. Londres: Random House, 1992.

WENGER, E. Communities of Practice: Learning, Meaning, and Identity. Cambridge: Cambridge University Press, 1998.

WENGER, E. Conceptual Tools for CoPs as Social Learning Systems: Boundaries, Identity, Trajectories and Participation. In Chris Blackmore (Ed.). Social Learning Systems and Communities of Practice (pp. 125-144), Londres, Springer, 2010.

WENGER, Etienne, MCDERMOTT, R. SNYDER, W. M. Cultivating Communities of Practice. Boston, MA: Harvard Business School Press, 2002.

ZEICHNER, K. M., LISTON, D. P. Reflective teaching: An introduction. Mahwah, NJ: Lawrence Erlbaum Associates, 1996. 